\title{
Performance of air-cathode microbial fuel cell with wood charcoal as electrodes
}

\author{
${ }^{1}$ Chai, L. F., ${ }^{2}$ Chai, L. C., ${ }^{1, *}$ Suhaimi, N. and ${ }^{2}$ Son, R. \\ ${ }^{1}$ Department of Cell and Molecular Biology,Faculty of Biotechnology and Biomolecular Sciences, \\ Universiti Putra Malaysia, 43400 UPM Serdang, Selangor, Malaysia. \\ ${ }^{2}$ Centre Of Excellence for Food Safety Research., Faculty of Food Science and Technology, \\ Universiti Putra Malaysia, 43400 UPM Serdang, Selangor, Malaysia.
}

\begin{abstract}
Local wood charcoal was used as the main component of the electrodes of an air-cathode microbial fuel cell (air-cathode MFC) in current study. The air cathode was build with finely milled charcoal powder and cement plaster as binder; while anode was made up of a packed bed of charcoal granules. Mangrove estuary brackish water was inoculated in the anodic chamber as the fuel and a source of exoelectrogens. The constructed fuel cell was monitored by measuring the potential over time. The MFC generated a stable power density at $33 \mathrm{~mW} / \mathrm{m}^{2}(0.5 \mathrm{~V})$ under a load of $200 \Omega$ after 72 hours of operation. An open circuit voltage (OCV) of $0.7 \mathrm{mV}$ was obtained after 15 hours operating under open circuit. The result of power generation by the constructed fuel cell indicating that wood charcoal could be used as electrode in an MFC and that brackish water contained potential exoelectrogens. However, further investigation and modification is required to increase the performance of the fuel cell.
\end{abstract}

Keywords: MFC, air-cathode, wood charcoal, brackish water, exoelectrogens

\section{Introduction}

In recent years, the research in microbial fuel cell (MFC) technology is evolving rapidly. Great expectations are directed to MFC technology because of the great potential of MFC as alternative renewable energy resources. Also, the technology caused no harm to the environment. The microbial fuel cell is a bio-electrochemical device that directly converts biochemical energy into electricity. The technology emphasizes on the usage of the available substrates from renewable sources and conversion of these substrates into harmless by-product with simultaneously production of electricity (Mohan and Kumar, 2008). Wastewater is an idea renewable sources that could practically used as substrates in MFC. Especially, food wastewater which is high in Chemical oxgen demand (COD) and Biological oxygen demand (BOD). For instance, molasses wastewater (Zhang et al., 2009) and beer brewery weatewater (Feng et al., 2008).

In MFC, microorganisms work as biocatalyst to breakdown the biomass into electrons and protons. Electrons were shuttled to anode and transferred to cathode where electrons, oxygen and protons combine to produce water (Li et al., 2009).

Presently, the studies are focus on improving the electricity generation and reducing the cost. Novel configuration (single-chamber MFCs, tubular MFCs, up-flows MFC) and electrode material (stainless steel, Pt loading cathode, and mediator-linked anode) have been developed (Logan et al., 2007). Single-chamber MFC has the advantages of simple configuration, sustainable operation and high power density over dual-chamber MFC, rendering it to become the mainstream of MFC's development (Ghangrekar and Shinde, 2007; Kim et al., 2007; Mohan et al., 2008). Nevertheless, most of the electrode materials (i.e. graphite and carbon) used in the MFC studies is expensive. MFC with high performance, low cost material and good scalable is necessary for the commercial application.

Charcoal is actually an impure carbon obtained by removing water and volatile constituent from vegetative plant. Through slow pyrolysis process, the resulting soft, brittle, lightweight, black, porous material containing $85 \%$ to $98 \%$ of carbon with the remainder consisting of volatile chemicals and ash. 
High quality charcoal (i.e. bamboo charcoal) could have resistance lower than $10 \Omega$ (Yang et al., 2009). Furthermore, the price for same amount of charcoal is cheaper than pure carbon or graphite. Therefore, charcoal holds a great promise in reducing the cost and brings the technology into real-world application.

The main objectives of current study were to investigate the potential application of wood charcoal, as a more economical material for electrodes in microbial fuel cell and up-scaling of the air-cathode MFC with wood charcoal. This is a preliminary study of MFC in Malaysia. For futher study, an large-scale MFC with application in actual molasses wastewater treatment should be study.

\section{Meterials and Methods}

\section{Brackish water}

Brackish water was collected from mangrove estuary in Kuala Sepetang, Perak and kept in $4^{\circ} \mathrm{C}$ until use. The brackish water was used as the inoculum for all MFC tests as it is without any modification such as $\mathrm{pH}$ adjustment or addition of nutrients.

\section{MFC design and operation}

Both MFC chambers were designed to have similar structure but with different volume capacity of $50 \mathrm{ml}$ and $450 \mathrm{ml}$. The MFC consisted of an anode, an air-cathode and an anodic chamber. The MFC with $50 \mathrm{ml}$ working volume, namely MFC-I, was used in the initial operation. The anode of the chamber was a piece of wood charcoal of $8 \mathrm{~cm} \times 1.2 \mathrm{~cm} \times 1.2 \mathrm{~cm}$, whereas the cathode was made of finely grounded wood charcoal powder and cement plaster mixture in 2:1 ratio.

MFC with larger capacity was termed MFC-II. It had a working volume of $450 \mathrm{ml}$ and wood charcoal beads (average diameter: $1 \mathrm{~cm}$; total volume: 130 $\mathrm{cm}^{3}$ ) as the anode. The construction of the air cathode was similar to MFC-I.

Both MFCs were initially connected to an external circuit with a single resistor (1000 $\Omega$ ) and allowed to operate for a few days. When a stable power generation was reached, the circuit was opened until a constant potential was obtained; then, polarization test was performed by varying the external resistance over a range of $100 \Omega-400 \mathrm{~K} \Omega$. The voltage was recorded. The power density was then calculated for each resistance as a function of the current density and polarization curve was plotted.

\section{Data capture and calculation}

The performance of the constructed MFC was monitored by linking the fuel cell to a computer via an eleven-channels terminal board connected to an ADC11 converter (Pico Technology Ltd., Cambridgeshire, UK). Real time data was recorded using PicoLog ${ }^{\circledR}$ version 5.16.2 recorder software and retrieval of the data was performed using the PicoLog ${ }^{\circledR}$ version 5.16.2 player software (Pico technology).

The current (I) in miliAmpere (mA) was calculated using Ohm's law, $\mathrm{I}=\mathrm{V} / \mathrm{R}$, where $\mathrm{V}$ is the measured voltage $(\mathrm{V})$ and $\mathrm{R}$ is the known external load value used for the test. The power density $\left(\mathrm{mW} / \mathrm{m}^{2}\right)$ of the MFC was also calculated based on the following formula, $\mathrm{P}=(\mathrm{I} \times \mathrm{V}) / \mathrm{A}$, where $\mathrm{A}$ is the surface area of air-cathode.

\section{Results and Discussion}

Preliminary experiment was conducted using MFC-I to demonstrate that wood charcoal can be used as an electrode to conduct electricity. Initially, MFC-I was operated across an external load of $1 \mathrm{~K} \Omega$, an average circuit voltage of $3.69 \mathrm{mV}$ was immediately generated within 24 hours. This initial voltage might be due to both the chemical and biological factors based on the difference of the potential between the anode (brackish water) and cathode (free oxygen in the air). The voltage increased dramatically due to the biological activity and stabilized at an average of $11.74 \mathrm{mV}$ over the following 11 days, resulting in an average power density of $0.014 \mathrm{~mW} / \mathrm{m}^{2}$ (normalized by the surface area of the cathode) (Figure 1A).

By varying the external resistance, the maximum power that was determined from the polarization curve was $0.04 \mathrm{~mW} / \mathrm{m}^{2}\left(0.6 \mathrm{~mA} / \mathrm{m}^{2}\right)$ at $10 \mathrm{~K} \Omega$ (Figure 1B). The generation of electricity gradually decreases from Day 16 and dropped below $6 \mathrm{mV}$ after Day 23 .

The MFC-II was constructed with a larger capacity volume to demonstrate the potential of large-scaled operation. It was inoculated with brackish water to measure the changes in power generation due to an increase in the working volume of the MFC. After 2 days operation, the fuel cell voltage reached a stable value of $399 \mathrm{mV}$ (Figure 2A). The maximum power density was $17.7 \mathrm{~mW} / \mathrm{m}^{2}(200 \Omega, 44.33 \mathrm{~mA} /$ $\mathrm{m}^{2}$ ) (Figure 2B). The power density is approximately 442 times higher than that obtained with MFC-I. The outcome of the experiments implies that the constructed fuel cell has great potential to be upscaled into larger industrial reactor for generation of greater power density.

Up-scaling of microbial fuel cell for greater electricity generation is not impossible, but may not be feasible due to the high-cost in construction of an MFC. However, with the utilization of cheaply available wood charcoal, it brings us one step forward 


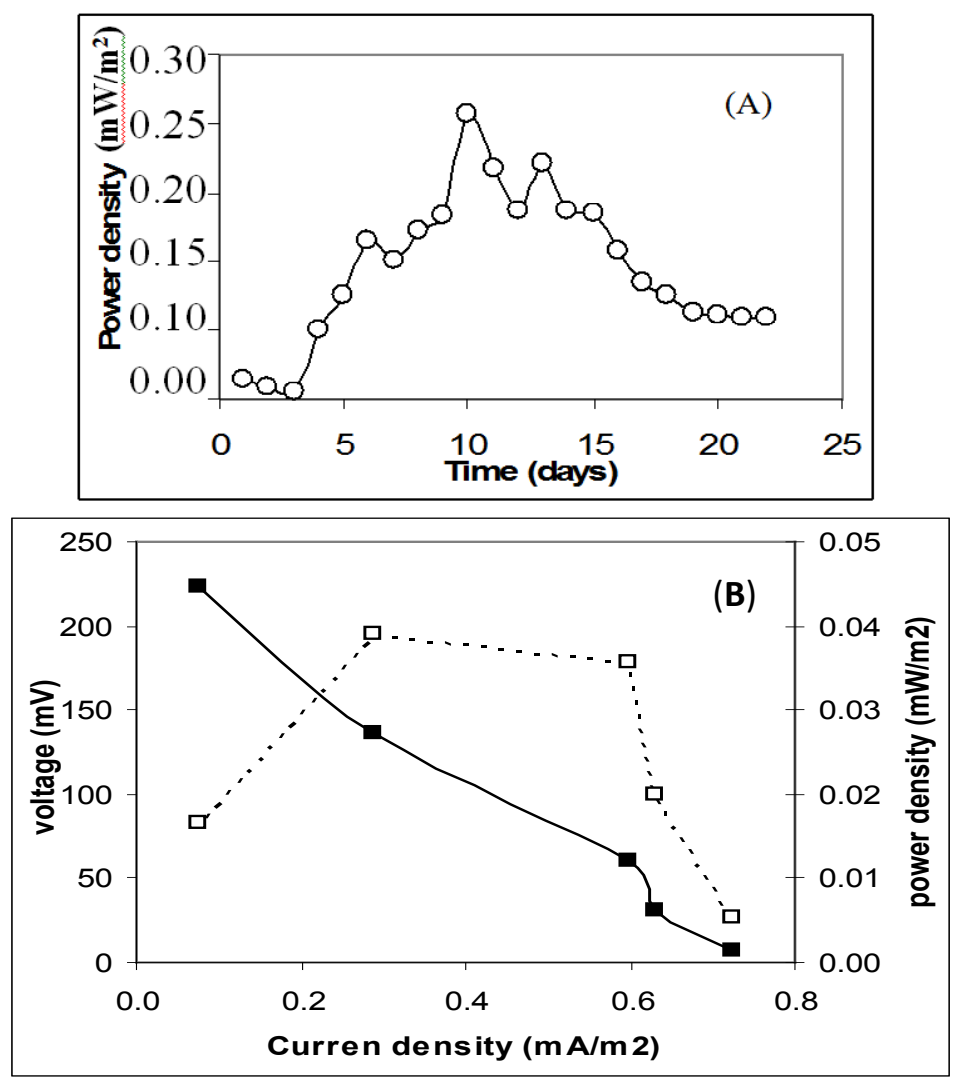

Figure 1. (A) Power generation with brackish water in the MFC-I (1K $\Omega$ ). (B) Voltage-current curve (closed square) and power curve (opened square) obtain by using external circuit of $100 \Omega-400 \mathrm{~K} \Omega$
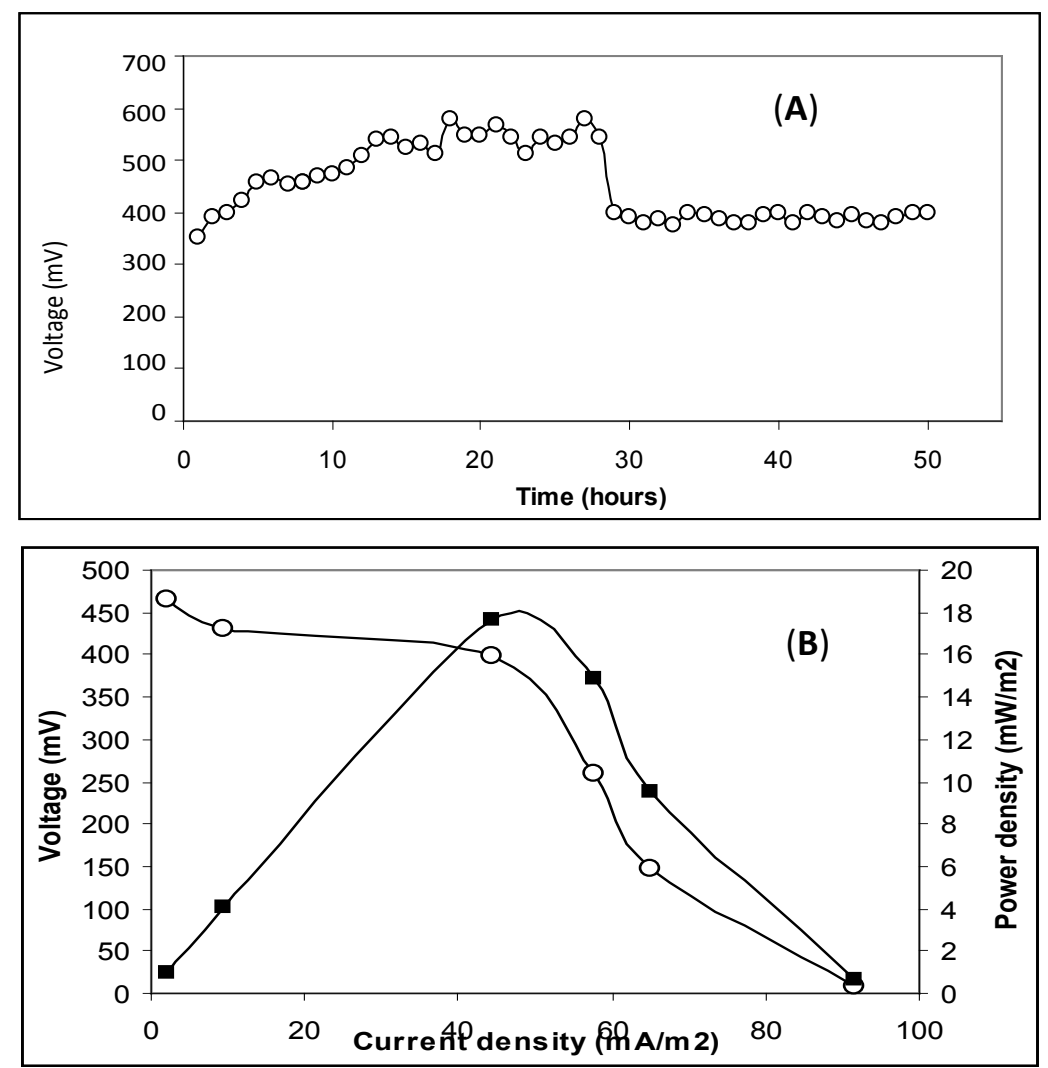

Figure 2. (A) Voltage generation with brackish water in the MFC-II. (B) Voltage-current curve (opened circle) and power curve (closed squre) obtained by using external circuit of $100 \Omega-400 \mathrm{~K} \Omega$ 


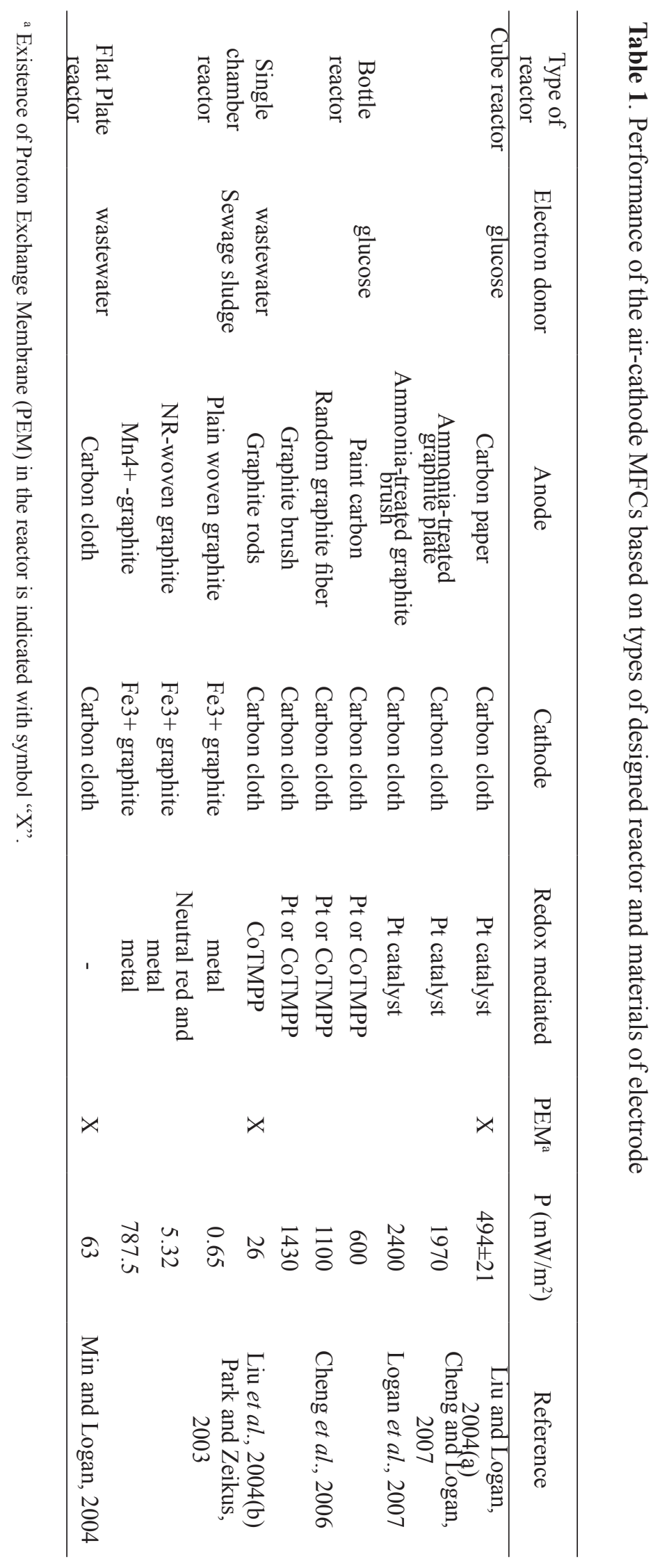


and closer to incorporating MFC technology into industrial application.

The architecture of an air cathode microbial fuel cell is not a novel design. The design was first reported by Sell et al. in early 1989. Over the time, there were many different materials with air-cathode based microbial fuel cell that have been reported. A list of air-cathode MFC described in other studies is summarized in Table 1 together with their electrode materials and catalyst. As shown in Table 1, the materials used as electrode were all of graphite and pure carbon. These reactors were reported to have considerable amount of power generation from these material. However, the use of expensive catalyst and proton exchange membrane are not preferable in up-scale application. Practical application of MFCs requires not only a matured structure with generation of high power but one that is also economical for mass production and to be operated on a large scale basis. However, such a reactor has yet to be developed at pilot or large scale to date.

Previously graphite and carbon was commonly used in MFC models, but in recent study, bamboo charcoal was used as an electrode in an air-cathode based MFC (Yang et al., 2009). The bamboo charcoal with resistance lower than $10 \Omega$ was selected and pre-treated to remove any impurity that can affect the performance of the charcoal as an electrode. The maximum power that was generated by the reactor is $0.144 \mathrm{~mW}$, producing a current of $0.6 \mathrm{~mA}(400$ $\Omega$ ) (Yang et al., 2009). Compared to the high quality bamboo charcoal used in the study by Yang et al. (2009), the resistance of the wood charcoal used in our study was more than $3 \mathrm{M} \Omega$ and the obstruction of conductivity may be due to the lower pyrolysis temperature applied during wood charcoal production used in current study $\left(220^{\circ} \mathrm{C}\right)$. A terminal pyrolysis temperature up to $700{ }^{\circ} \mathrm{C}$ is needed to efficiently carbonize vegetative bamboo into high conductivity charcoal that gives the charcoal significant property to work well as an electrode. Cellulose and lignin in the vegetative wood would be transformed into graphitic particles at temperature higher than 700 ${ }^{\circ} \mathrm{C}$ (Tashimistu et al., 2000). Therefore, it is highly possible that the performance of the wood charcoal air-cathode microbial fuel cell could be greatly improved with the use of high conductivity wood charcoal produced with an increasing terminal pyrolysis temperature up to $700{ }^{\circ} \mathrm{C}$. Nonetheless, further study is required to confirm the relationship of pyrolysis temperature against electrode conductivity in charcoal production.

\section{Conclusion}

This paper presented a preliminary study on the performance of the designed MFC. Electricity was generated using brackish water, at a power density that depends greatly on the volume capacity of the MFC. The findings from this study imply that wood charcoal could be used as the electrodes of the MFC. The readily available low cost of wood charcoal in this country can be a solution for the issues in economically scale-up of MFC. Further studies are required to determine the limiting factors and modifications in order to improve the performance the designed MFC.

\section{Acknowledgement}

This research was financially supported by the Research University Grants (RUGS) (91029) from Universiti Putra Malaysia.

\section{References}

Feng, Y. J., Wang, X., Logan, B. E. and Lee, H. 2007. Brewery wastewater treatment using air-cathode microbial fuel cells. Applied Microbiology Biotechnology 78: 873-880.

Ghangrekar, M. M. and Shinde, V. B. 2007. Performance of membrane-less microbial fuel cell treating wastewater and effect of electrode distance and area on electricity production. Bioresource Technology 98: 2879-2885.

Kim, J. R., Jung, S. H., Regan, J. M. and Logan, B. E. 2007. Electricity generation and microbial community analysis of alcohol powered microbial fuel cell. Bioresource Technology 98 : 2568-2577.

Li, Z. J., Zhang, X. W., Zeng, Y. X. and Lei, L. C. 2009. Electricity Production by an overflow-type wettedwall microbial fuel cell. Bioresource Technology 100 : 2552-2555.

Logan, B.E., Cheng, S., Watson, V. and Estadt, G. 2007. Graphite fiber brush anodes for increased power production in air-cathode microbial fuel cells. Environmental Science Technology 41(9): 33413346.

Mohan, S. V., Raghavulu, S. V. and Sarma, P. N. 2008. Influence of anodic biofilm growth on bioelectricity production in single chambered mediatorless microbial fuel cells using mixed anaerobic consortia. Biosensors and Bioelectronics 24: 41-47.

Mohan, Y., Kumar, S. M. M. and Das, D. 2008 Electricity generation using microbial fuel cells. International 
Journal of Hydrogen Energy 33: 423- 426.

Sell, D., Kramer, P. and Kreysa, G. 1989. Use of an oxygen gas diffusion cathode and a three dimensional packedbed anode in a bioelectrochemical fuel cell. Applied Microbiology Biotechnology 31(2): 211-213.

Tashimistu, H., Yuji, I., Emiko, K., Kenji, Y. and Kohtaru, K. 2000. Onion-like graphitic particles observed in wood charcoal. Journal of Wood Science 46: 89-92.

Yang, S. Q., Jia, B. Y. and Liu, H. 2009. Effect of the Pt loading side and cathode-biofilm on the performance of a membrane-less and single-chamber microbial fuel cell. Bioresource Technology 100: 1197-1202.

Zhang, B. G., Zhao, H. Z., Zhou, S. G., Shi, C. H., Wang C. and Nia, J. R. 2009. A novel UASB-MFC-BAF integrated system for high strength molasses wastewater treatment and bioelectricity generation. Bioresources Technology 23: 5687-5693. 